\section{Proposed ASTM Standard Test Method for \\ ELEVATED TEMPERATURE \\ FLEXURAL STRENGTH, \\ CREEP STRAIN, AND \\ CREEP TIME TO FAILURE \\ FOR ADVANCED CERAMICS}

Ralph F. Krause, Jr.

U.S. DEPARTMENT OF COMMERCE Natlonal Institute of Standards and Technology Ceramics Division

Galthersburg, MD 20899
PIL

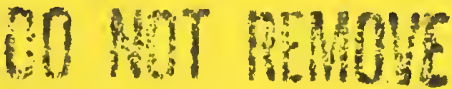

U.S. DEPARTMENT OF COMMERCE Robert A. Mosbacher, Secretary MATIONAL INSTITUTE OF STANDARDS AND TECHNOLOQY

Raymond G. Kammer, Acting Director 



\section{Proposed ASTM Standard Test Method for}

\section{ELEVATED TEMPERATURE \\ FLEXURAL STRENGTH, \\ CREEP STRAIN, AND CREEP TIME TO FAILURE FOR ADVANCED CERAMICS}

Ralph F. Krause, Jr.

U.S. DEPARTMENT OF COMMERCE

Natlonal Institute of Standards

and Technology

Ceramics Divislon

Galthersburg, MD 20899

Prepared for

Amerlcan Soclety for Testlng and Materlals Phlladelphla, PA 19103

ASTM Commlttee C28 on Advanced Ceramles

Dr. Kamal E Amln

Chalrman of Subcommittee on Propertles Norton Company

Norton, MA 01532

This document ls part of the ASTM standards process and Is for ASTM committee use only. It shall not be reproduced or clrculated or quoted, In whole or in parts, outslde of ASTM Committee activitles except with the approval of the Committee Chalrman.

July 1989

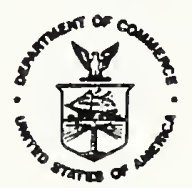

U.S. DEPARTMENT OF COMMERCE Robert A. Mosbacher, Secretary NATIONAL INSTTUUTE OF STANDARDS AND TECHNOLOQY

Raymond Q. Kammer, Aeting Director 

ELEVATED TEMPERATURE FLEXURAL STRENGTH, CREEP STRAIN, AND CREEP TIME TO FAILURE FOR ADVANCED CERAMICS

Ralph F. Krause, Jr.

National Institute of Standards and Technology

Gaithersburg, MD 20899

(301) $975-5781$

Version II, June 1, 1989

ASTM Subcommittee C28.01 on Properties of Advanced Ceramics

1. Scope

1.1 This test method covers the determination of flexural strength, creep strain, and creep time to failure for advanced ceramics at elevated temperatures, generally between 1200 and $2000 \mathrm{~K}$. Rectangular beam specimens, nominally $3 \mathrm{~mm} \times 4 \mathrm{~mm} \times 50 \mathrm{~mm}$, are loaded in four-point flexure. Strengths are evaluated from the maximum bending moments which are required to rupture individual specimens in dynamic loading. The creep strains of individual specimens with fixed bending moments at fixed temperatures are evaluated from load-point displacements as a function of time. The secondary creep-strain rate, which is invariant with time, is evaluated as a function of applied stress and temperature. Creep time to failure is also correlated with the secondary creep-strain rate.

1.2 While many materials may be tested in air, an inert gas environment must be provided for those materials which react with oxygen at elevated temperatures. A controlled gas environment must also be provided for any material which evolves toxic vapors.

1.3 Values expressed in this test method are in the International System of Units (SI). 
2. Applicable Documents

\subsection{ASTM Standards}

E4 Practice for Load Verification of Testing Machines ${ }^{1}$

E83 Practice for Verification and Classification of Extensometers ${ }^{1}$

E139 Practice for Conducting Creep, Creep-Rupture, and Stress-Rupture

Tests of Metallic Materials ${ }^{1}$

E220 Method for Calibration of Thermocouples by Comparison

Techniques ${ }^{2}$

E230 Temperature-Electromotive Force (EMF) Tables for Standardized

Thermocouples ${ }^{2}$

\subsection{ASTM Proposal}

Test Method for Flexural Strength of Advanced Ceramics at Ambient Temperature ${ }^{3}$

3. Symbols

A Coefficient of secondary creep-strain rate, Eq (16).

b Specimen width normal to loading direction, Fig. 1.

C Compliance of specimen and machine combined, C $=y / F, E q$ (5).

d Diameter of loading pin, Fig. 1 .

$d_{1}$ Distance between loading-pin stops on minor span of flexure platens, Fig. 1.

$\mathrm{d}_{2}$ Distance between loading-pin stops on major span of flexure platens, Fig. 1 .

$f$ Fraction of full-scale load, Eq (3).

F Compressive force applied to flexure platens, Eq (7).

$F_{\mathrm{m}}$ Maximum compressive force applied to flexure platens to produce specimen failure in dynamic loading.

$F_{3} \quad$ Full scale load selected for a strength test, Eq (3).

${ }^{1}$ Annual Book of ÁSTM Standards, Vol 03.01.

${ }^{2}$ Annual Book of ASTM Standards, Vol 14.03.

${ }^{3}$ G. Quinn, M. Slavin, and F. Baratta, ASTM Subcommittee C28.01, Properties of Advanced Ceramics, September 1988. 
$\dot{\mathrm{F}} \quad$ Loading rate, $\dot{\mathrm{F}}=\mathrm{dF} / \mathrm{dt}, \mathrm{Eq}$ (3).

h Specimen height parallel to loading direction, Fig. 1.

$\ell$ Specimen length.

$\ell_{1} \quad$ Minor loading span, Eq (1).

$\ell_{2}$ Major loading span, Eq (2).

M Monkman-Grant constant, Eq (17).

$\mathrm{n}$ Creep index, Eq (15).

Q Activation energy, Eq (16).

$\mathrm{R}$ Gas law constant, $\mathrm{R}=8.3143 \mathrm{~J} \cdot \mathrm{K}^{-1} \mathrm{~mol}^{-1}$.

S Flexural strength, section 9.1.2.

$\mathrm{S}_{\boldsymbol{r}} \quad$ Flexural strength at $\mathrm{T}_{\mathrm{r}}, \mathrm{Eq}(8)$.

$t$ Interval of time since application of load in a creep test.

$t_{d} \quad$ Interval of time during dynamic loading, Eq (3).

$t_{f}$ Creep time to failure of specimen, Eq (17).

T Absolute temperature.

$\mathrm{T}_{\mathrm{r}}$ Temperature at which regression of strength commences, Eq (8).

$x \quad$ Length of chart paper during dynamic loading, Eq (5).

$\dot{x}$ Chart speed selected for a strength test, $\dot{x}=d x / d t, E q(5)$.

y Load-point displacement of the specimen and machine.

$y_{c} \quad$ Load-point displacement of the specimen during creep, Eq (6).

y Crosshead speed selected for a strength test, $\dot{y}=d y / d t, E q(4)$.

$\propto \quad$ Temperature coefficient of strength regression, Eq (8).

$\beta$ Coefficient in Monkman-Grant function, Eq (17).

$\epsilon$ Creep strain of the outer fiber of a flexure specimen with a fixed bending moment at a fixed temperature, Eq (10).

$\epsilon_{1} \quad$ Linear creep strain of the outer fiber of a specimen, Eq (11).

$\epsilon_{\text {so }} \quad Y$-intercept from extrapolation of secondary mode of creep strain to initial time, Eq (12).

$\stackrel{\circ}{\epsilon}$ Creep-strain rate, $\dot{\epsilon}=\mathrm{d} \epsilon / \mathrm{d} t$, Eq (14).

$\stackrel{\circ}{\circ}$ Initial creep-strain rate, Eq (13).

$\dot{\epsilon}_{\mathrm{s}} \quad$ Secondary creep-strain rate, Eq (12).

$\sigma$ Applied creep stress on the outer fiber of a specimen, Eq (9).

$\sigma_{1} \quad$ Linear-elastic stress on the outer fiber of a specimen, Eq (7).

$\tau$ Time coefficient of primary creep strain, Eq (13). 
4. Significance and Use

4.1 High-strength ceramic materials, which are generally characterized by small grain sizes $(<50 \mu \mathrm{m})$ and bulk densities near their theoretical densities, are candidates for load-bearing applications at elevated temperatures. These applications involve components such as structural beams and turbine blades which are subjected to bending moments. Flexural strength and creep properties are used to compare materials in development, to control their quality in production, and to design structures based on these material property characteristics. Futhermore, many investigators prefer to conduct flexure tests on ceramic materials because these tests avoid the complexity of gripping and alignment of specimens.

4.2 Several factors affect the measurement of flexural strength and creep properties. Flexural strength depends mainly on the most severe intrinsic flaw in the outer fiber of the flexure specimen. Any slow crack growth which is caused by reaction with the environment during loading reduces the strength. The time that a specimen is treated at an elevated temperature allows for grain growth, which is often correlated with increased flaw size; but healing or blunting of intrinsic flaws at the elevated temperature may have a countervailing effect.

4.3 When a flexure specimen is subjected to a given bending moment at an elevated temperature, creep strain occurs as a function of time. Stresses can concentrate at points along the surface of intrinsic flaws, and extra damage can evolve as a consequence of cavitation at the interfaces among grains. As the cavity density increases, the cavities can coalesce to a critical size, which can be related to the creep strain of the outer fiber at failure $[1,2]$.

4.4 Primary flexural creep, which is characterized by a creep strain rate that decreases as a function of time, can persist for a prolonged period. During this period, the initial linear-elastic distribution of bending stresses is transformed to a final non-linear secondary distribution, where creep strain rate becomes independent of time. The normal strain distribution along the beam height is always linear in agreement with Bernoulli's hypothesis although the position of the neutral 
strain axis is not stationary. The migration of the neutral strain axis from the original geometric center towards the compression side of the specimen, as the creep test proceeds, has been confirmed experimentally [3].

4.5 Certain conditions are specified in this test method to control the measurement of flexural strength at elevated temperatures. Dynamic loading at a rapid rate is used to minimize the effects of creep and environmentally enhanced crack growth. Specimens are carefully ground and polished to minimize machining damage. The flexure platens were designed to minimize misalignment, friction, and contact-stress errors.

\section{Apparatus}

\subsection{Flexure Platens}

5.1.1 Four-point flexure platens shall have minor and major spans,

$$
l_{1}=\mathrm{d}_{1}-\mathrm{d}
$$

and

$$
\ell_{2}=d_{2}+d
$$

respectively, such that $2 \leq \ell_{2} / \ell_{1} \leq 4$ and $30 \mathrm{~mm} \leq \ell_{2} \leq 50 \mathrm{~mm}$, Fig. 1 .

5.1 .2 The loading pins shall have uniform diameters, $4 \mathrm{~mm} \leq \mathrm{d} \leq 8 \mathrm{~mm}$, within a tolerance of $0.02 \mathrm{~mm}$.

5.1.3 The support base and load-bearing surfaces of the platens on which the loading pins roll shall have finishes which are machined flat and parallel within $0.02 \mathrm{~mm}$ tolerance.

NOTE 1--The loading pins must be free to roll to relieve frictional constraints. The presence of friction between a beam specimen and fixed loading pins in a flexure test could produce a systematic error in the failure stress as high as 128 [4]. When loading pins which are free to roll are used, extension of the outer fiber of the beam specimen tends to cause the major-span pins to roll outward. Contraction from bowing of the beam specimen tends to produce the reverse motion. The superposition of these tendencies produces a net effect, first of outward motion of the 
major-span pins, followed by their reverse motion. The pins will have returned to their initial positions against their stops when the elastic strain of the outer fiber reaches $3 \%$, as estimated for the dimensions used in this test method [5]. The minor-span pins will roll in an opposite manner.

5.1.4 A hemispherical compression tool, Fig. 1, shall be installed to accomodate any lack of parallelism in the ends of the loading rams.

5.1.5 The platens shall have sufficient size so that any strain in the platens is small compared to that in the specimen when loads are applied.

5.1.6 The platens and rollers shall be made from the same material. It should exhibit considerable hardness and low creep characteristics at elevated temperatures, for example, a highly dense, $99 \%$ silicon carbide ceramic.

5.1.7 A square jig shall be used to center the specimen between the major and minor spans. The platens shown in Fig. 1 were designed to facilitate alignment.

\subsection{Load Testing Machine}

5.2.1 The accuracy of the testing machine, whether it is used in dynamic loading for strength tests or in deadweight loading for creep tests, shall be within the $1 \%$ permissible variation of accuracy specified in Practice E4.

5.2.2 The rate of dynamic loading for strength tests,

$$
\stackrel{\circ}{F}=f \cdot F_{s} / t_{d}
$$

shall be selected so that the time required to attain full scale load, $t_{d} / f$, is between 5 and $10 \mathrm{~s}$.

NOTE 2--The lower limit of $t_{d} / f$ is believed to exceed the response time required for most machines to indicate the load within the variation of accuracy in 5.2.1. 
5.2.3 The full scale load, $F_{s}$, shall be selected so that the maximum force, $F_{m}$, which causes specimen failure in dynamic loading, is between $F_{s} / 2$ and $F_{s}$. Generally, the full scale load will be between 100 and $1000 \mathrm{~N}$ for the size of ceramic specimens specified in this test method.

5.2.4 The compressive force, $F$, which is applied to the specimen in the flexure platens shall be transmitted through a pair of loading rams which protrude through holes in the top and bottom of a furnace. The ends of the rams should be ground normal to their longitudinal axes. The rams should be vertically aligned through adjustable fixtures which are attached to the loading machine. The rams should have sufficient cross-sectional area so that stresses in the rams will produce negligible creep-strain in them during prolonged tests at elevated temperatures.

NOTE 3--Recrystallized 998 silicon carbide rods with approximately 20 $\mathrm{mm}$ diam should serve this purpose. Hemispherical caps of hardened steel at the water-cooled ends of the rams should prevent spalling of ram ends and facilitate ram alignment.

5.2.5 The load transducer should have such quality that any component of force other than that in the vertical direction produces a negligible response in the transducer within the variation of accuracy specified in section 5.2.1.

5.2.6 The testing machine should be erected to secure reasonable freedom from vibration and impact due to external causes. Precautions should be taken to minimize the transmission of shock to neighboring test machines and specimens when a specimen fails.

5.2.7 For high-temperature testing of materials which are readily attacked by their environment (such as oxidation of a material in air), the specimen may have to be enclosed in a sealed chamber so that it can be tested in a vacuum or inert-gas atmosphere. When such equipment is used, the necessary corrections to obtain true specimen loads must be made. For instance, compensation must be made for differences in pressures inside and outside of the chamber and for any load variation due to sealing-ring friction, bellows, or other features. 


\subsection{Displacement Transducer}

5.3.1 The equipment for measuring the deflection of the flexure beam in the creep test should have a long-term stability within a variation of $10 \mu \mathrm{m}$, and a sensitivity which can detect deflections as small as $2 \mu \mathrm{m}$.

5.3.2 Since direct deflection measurements at elevated temperatures are difficult to make, a suitable and inexpensive method involves the remote measurement of load-point displacement. A linear voltage displacement transducer should be attached to the water-cooled portion of the loading train and shielded from any thermal radiation of the furnace.

5.3.3 When deformation of the flexure specimen is indicated by remote measurement of the load-point displacement, a reference set of duplicate loading rams must be installed in the furnace. A block which undergoes negligible creep at the loads and temperatures used shall be substituted in place of a specimen. Any displacement measured for the block with the same load as the specimen reflects changes in the test facility due to electronic drift, to fluctuations in the ambient temperature, or to creep of the machine itself.

5.4 Heating Apparatus

5.4.1 The apparatus for heating the specimens should provide temperatures up to $2000 \mathrm{~K}$ and a variation of temperature control within $1 \mathrm{~K}$ at a given point in the hot zone for prolonged time periods.

5.4.2 Suitable heating can be achieved by electic resistance heating of molybdenum disilicide elements which axe mounted inside a thermally insulated cavity and which radiate directly to the specimen, ordinarily in air at barometric pressure.

5.4.3 The furnace shell should be water-cooled by a thermostated bath to minimize temperature variations in the loading frame and to protect the transducers which are used to measure applied load and load-point displacement.

5.4.4 A coil of flexible, reinforced tubing should be arranged to cool the ram holders in such a manner as to impart negligible torque to the rams.

5.4.5 The furnace chamber should be capable of being made gas tight to accomodate a controlled gas environment if it is specifically required for a special test. 


\subsection{Temperature Measuring Apparatus}

5.5.1 The method of temperature measurement must be sufficiently reliable to ensure that the temperature of the specimen has a variation of accuracy within 3 kelvin over prolonged periods of time.

5.5.2 For this purpose the temperature should be measured with a platinum and 68 rhodium versus platinum and $30 \%$ rhodium thermocouple, using pure copper extension leads to connect the thermocouple to a potentiometer or voltmeter.

5.5.3 The voltage measuring instrument should have a sensitivity of $2 \mu \mathrm{V}$ and a variation of long-term stability within $10 \mu \mathrm{V}$.

5.5.4 The thermocouple wires should be supported in 998 pure $\mathrm{Al}_{2} \mathrm{O}_{3}$ double-bore rods within the furnace, and the thermocouple junction should be exposed and located near the specimen.

5.5.5 The reading of the operating thermocouple should be checked occasionally with that of a calibrated thermocouple of the same type, which is introduced to a given point of the hot zone of the furnace only long enough to become equilibrated. In this way any drift in calibration of the operating thermocouple may be monitored and corrected while the calibrated thermocouple has limited exposure to possible contamination.

\subsection{Recording Apparatus}

5.6.1 Dynamic loading for the strength test must be recorded continuously as a function of time in order to evaluate the maximum load required to rupture the flexure specimen. A paper chart recorder with adjustable chart speed should suffice for this purpose.

5.6.2 If a paper chart recorder is used, the pen response of the recorder should require no more than $5 \mathrm{~s}$ for it to traverse the full scale of the chart during dynamic loading and to indicate the full scale load with an error less than 18.

5.6.3 Load-point displacement in the creep tests must be recorded at sufficiently frequent time intervals so that observed changes in the displacement are less than 58. Automatic digital recording with adjustable frequency of operation should suffice for this purpose. The optional feature of being able to communicate collected data to an electronic computer will facilitate analysis of the data. 
5.6.4 A suitable stop clock should measure the elapsed time between complete application of the load in a creep test and the time at which rupture of the specimen occurs, within a variation of accuracy of 18 .

\section{Test Specimens}

6.1 Similar specimens shall be used for both the strength tests and the creep tests.

6.2 Specimens may be taken from different locations in the same sample or from different samples, but the nature and composition of the initial reactants and the processing conditions to fabricate the finished product must be identical to compare the test results statistically.

6.3 Samples shall be diamond-sawed to make rectangular beam specimens with the nominal dimensions: $h=3 \mathrm{~mm}, 3 \mathrm{~mm} \leq \mathrm{b} \leq 5 \mathrm{~mm}$, and $\ell_{2}+2 \mathrm{~h} \leq \ell \leq \ell_{2}+4 \mathrm{~h}$.

6.4 Opposite sides of the specimens should be ground flat and parallel. This operation should be performed on the specimens in their longitudinal direction with a $30 \mu \mathrm{m}$ diamond wheel which should be advanced each time no more than $20 \mu \mathrm{m}$, following 6 passes over the surface.

6.5 The prospective tensile surface of each specimen should be polished with 6 to $9 \mu \mathrm{m}$ diamond paste to produce a finish which is adequate for optical microscopic examination.

6.6 Specimens should be carefully cleaned in alcohol or other suitable solvent and dried in warm air prior to testing.

\section{Calibrations}

7.1 A representative thermocouple shall be calibrated by ASTM Method E220, "Calibration of Thermocouples by Comparison Techniques."

7.2 The load measuring system shall be calibrated by ASTM Practice E4. "Load Verification of Testing Machines."

7.3 The displacement transducers shall be calibrated by ASTM Practice E83, "Verification of Classification of Extensometers." 


\section{Procedures}

8.1 Mounting the Specimen

8.1.1 Measure the diameter of the loading pins, $d$, and the distance between stops of the minor and major spans of the flexure platens, $d_{1}$ and $\mathrm{d}_{2}$, respectively, within $0.02 \mathrm{~mm}$ variation of accuracy.

8.1.2 Measure the cross-sectional dimensions, $b$ and $h$, in the middle of the beam specimen within $0.02 \mathrm{~mm}$ variation of accuracy.

8.1.3 Mount the beam specimen in the center of the major and minor spans of the flexure platens with the loading pins in their initial positions against their stops. Use a combustible cement to tack all the components together to facilitate their placement between the loading rams in the furnace.

8.1.4 Apply a preliminary load of approximately $5 \mathbb{N}$ to the assembly of the specimen and flexure platens in order to hold the assembly together while the cement is burned away during heat up of the furnace.

8.1.5 As the preliminary load is maintained, heat the furnace to the test temperature and condition the specimen at the test temperature for at least $1 \mathrm{~h}$ to assure thermal equilibration prior to initiation of the test.

8.2 Strength Tests

8.2.1 Apply dynamic loading as specified in section 5.2.2 until the specimen ruptures.

8.2.2 In a gear-driven loading machine, the crosshead speed which is required for the specified loading rate is given by

$$
\dot{y}=C \cdot f \cdot F_{s} / t_{d}
$$

8.2.3 The combined compliance of the specimen and the gear-driven loading machine is determined experimentally prior to the test from

$$
C=x \cdot \dot{y} /\left(\dot{x} \cdot f \cdot F_{s}\right)
$$

where $\dot{y}$ is a preliminary crosshead speed, for example, $\dot{y}=0.5 \mathrm{~mm} / \mathrm{min}$. 
8.2.4 The chart speed, $\dot{x}$, which is used to measure the time of dynamic loading by a gear-driven machine, is selected so that the chart length, $x$, during the dynamic loading is greater than $10 \mathrm{~cm}$.

8.2.5 Repeat the strength test at 5 or more different temperatures as appropriate between 1200 and $2000 \mathrm{~K}$ with temperature intervals of 100 kelvin. Repeat the strength test with 4 or more specimens at each temperature.

\subsection{Creep Tests}

8.3.1 When the furnace has thermally equilibrated at the test temperature, adjust the displacement transducer near its zero reading.

8.3.2 Apply the complete, deadweight load, and simultaneously initiate the timing of the creep test.

8.3.3 Read the load-point displacement of the specimen periodically, following the elastic displacement, as specified in section 5.6.3.

8.3.4 If the load-point displacement is read remotely, correct it for thermal variations in the length of the loading frame as specified in section 5.3.3, for example,

$$
y_{c}=\left(y-y_{0}\right)-\left(y^{\prime}-y_{0}^{\prime}\right)
$$

where the subscript zero denotes the staxt of the creep test and the prime symbol denotes the reference set of loading rams.

8.3.5 Monitor both the fixed load and test temperature occasionally to verify the constancy of their settings.

8.3.6 Conduct the creep test until the specimen fails or until the minimum strain rate appears invariant within 58 for more than one-half the elapsed time of the creep test.

8.3.7 Repeat the creep test at 4 or more different temperatures as appropriate between 1200 and $2000 \mathrm{~K}$ with temperature intervals of approximately 50 kelvin or greater.

8.3.8 Repeat the creep test at 4 or more different loads at each temperature. Select the loads to give minimum creep-strain rates which vary over a range by a factor of 50 or greater. 
9. Data Analysis

\subsection{Strength Tests}

9.1.1 The linear-elastic stress on the outer fiber of the flexure specimen is given by

$$
\sigma_{1}=3 \cdot \mathrm{F} \cdot\left(l_{2}-l_{1}\right) /\left(2 \cdot \mathrm{b} \cdot \mathrm{h}^{2}\right)
$$

9.1.2 Calculate the flexural strength of each specimen, $\mathrm{S}=\sigma_{1}$, using the observed maximum load required to rupture the specimen, $F_{m}=F$. The dynamic loading of the ceramic flexure specimen is assumed to be linearelastic.

NOTE 4--Corrections for thermal expansion of the specimen and flexure platens are not deemed necessary since these corrections are generally less than 18 for many ceramic materials.

\subsubsection{If the strength is observed to regress with increasing} temperature, Fig. 2, the regression can be represented by a straight line,

$$
S=S_{r} \cdot\left[1-\propto\left(T-T_{r}\right)\right]
$$

where the coefficients $\propto$ and $T_{r}$ are evaluated by a least-squares fit, and $S_{x}$ is the room-temperature strength which is assumed to be the strength at the temperature, $\mathrm{T}_{\mathrm{r}}$.

9.2 Creep Stress and Creep Strain

9.2.1 The applied stress, $\sigma$, in four-point flexure and the corresponding creep strain, $\epsilon$, are calculated by the method of Hollenberg, Terwilliger, and Gordon [6]. Their approach assumes the constitutive law of a material, namely, that the strain (and strain rate) at a given temperature can be separated into individual functions of stress and time. Norton's power-law function of stress, $\sigma^{n}$, where $n$ is the creep index, is generally accepted as the stress function [7]. 
9.2.2 When the neutral axis of flexure is assumed to be at the center of the beam, the stress on the outer fiber of the beam is given by

$$
\sigma / \sigma_{1}=(2 n+1) / 3 n
$$

NOTE 5--The migration of the neutral axis of flexure from the geometric center is not discernable experimentally until considerable creep strain has occurred, generally greater than $0.5 \%$ [3]. Since correction for this migration is complicated and generally small, it is believed not to be warranted for the purposes of this test method.

9.2.3 The corresponding creep strain of the outer fiber is given by

$$
\epsilon / \epsilon_{1}=(n+2)\left(l_{2}+2 l_{1}\right) / 3\left[l_{2}+l_{1}(n+1)\right]
$$

where

$$
\epsilon_{1}=6 \cdot h \cdot y_{c} /\left(l_{2}{ }^{2}+l_{1} l_{2}-2 l_{1}{ }^{2}\right)
$$

9.2.4 Since the creep index, $n$, has yet to be evaluated, only the linear-elastic values of stress and strain, $\sigma_{1}$ and $\epsilon_{1}$, can be calculated from Eqs (7) and (11), respectively, at this stage of the analysis. Thus, $\epsilon_{1}$ reflects the load-point displacement which was measured as a function of time.

\subsection{Time Function of Creep Strain}

9.3.1 A customary creep model [8] is adopted to represent creep strain as a function of time. This model describes an elastic element in parallel with a viscous element, and this compound is in series with another viscous element. The model gives the time function of strain as

$$
\epsilon=\epsilon_{\mathrm{so}} \cdot[1-\exp (-t / \tau)]+\stackrel{\circ}{\epsilon}_{\mathrm{s}} t
$$

where

$$
r=\epsilon_{\mathrm{s}} /\left(\dot{\epsilon}_{0}-\dot{\bullet}_{\mathrm{s}}\right)
$$

The identity of the parameters, $\epsilon_{s_{0}}, \dot{\epsilon}_{0}$, and $\dot{\epsilon}_{s}$, is consistent with the derivative of $\mathrm{Eq}$ (12), namely, 


$$
\dot{\epsilon}=\left(\epsilon_{\mathrm{so}} / \tau\right) \cdot \exp (-t / \tau)+\dot{\epsilon}_{\mathrm{s}}
$$

9.3.2 Preliminary values of the coefficients, $\dot{\epsilon}_{\mathrm{s}}, \epsilon_{\mathrm{so}}$, and $r$, can be estimated by a least-squares fit of $\mathrm{Eq}$ (12) in which $\epsilon_{1}$ is substituted for $\epsilon$. A first approximation of these parameters for the least-squares fit may be obtained graphically, Fig. 3. Drawing a straight line through the secondary mode of creep leads to first approximations of $\dot{\epsilon}_{\mathrm{s}}$ from the slope of the straight line and of $\epsilon_{\text {so }}$ from its y-intercept. Drawing a tangent line to the creep data at the origin leads to $\dot{\epsilon}_{0}$.

9.3.3 In this manner evaluate preliminary values of $\dot{\epsilon}_{\mathrm{s}}, \epsilon_{\mathrm{so}}$, and $\tau$ for each creep test.

9.4 Stress and Temperature Functions

9.4.1 The creep index, $n$, can first be estimated at the respective temperatures as the slope of the logarithm of the secondary creep-strain rate versus the logarithm of applied stress,

$$
\mathrm{n}=\partial \log \left(\dot{\epsilon}_{\mathrm{s}}\right) / \partial \log (\sigma)
$$

The approximations for $\stackrel{\circ}{\epsilon}_{s}$ and $\sigma$ which were derived from $\epsilon_{1}$ and $\sigma_{1}$, respectively, can be appropriately substituted in Eq (15) because the constant factors on the right-hand sides of Eqs (9) and (10) merely shift the logarithmic scales, but the slope remains the same.

9.4.2 If the creep index appears to be invariant with both stress and temperature within the variation of the precision of the measurements, Fig. 4, the secondary creep-strain rate can be described by the product of Norton's power-law function of applied stress [7] and Arrhenius' function of inverse temperature [9],

$$
\stackrel{\circ}{\epsilon}_{s}=A \cdot \sigma^{n} \cdot \exp (-Q / R T)
$$

9.4.3 Evaluate the coefficients, $A, n$, and $Q$ by a least-squares fit of the logarithm of $\mathrm{Eq} \mathrm{(16)} \mathrm{for} \mathrm{all} \mathrm{the} \mathrm{creep} \mathrm{tests} \mathrm{which} \mathrm{lie} \mathrm{within} \mathrm{the}$ bounds of the criteria of section 9.4.2. Displays of the least-squares fit for the coefficients, $\mathrm{n}$ and $\mathrm{Q}$, are conveniently shown by Figures 5 and 6 , respectively. 
NOTE 6--A transformation in the structure of the ceramic or a change in the creep mechanism can result in a change in the creep index; therefore, the different regimes must be analysed separately.

9.4.4 The linear elastic approximations of the applied stress and the secondary creep-strain rate used in Eq (16) can be corrected by Eqs (9) and (10), respectively.

\subsection{Creep Time to Failure}

9.5.1 The empirical expression of Monkman and Grant [10] has had a significant influence on the development of creep fracture models. The general form of their expression is given by

$$
\dot{\epsilon}_{s}^{\beta} \cdot t_{f}=M
$$

9.5.2 Evaluate the coefficients $\beta$ and $M$ by a least-squares fit of the logarithm of Eq (17). A typical display of the least-squares fit is shown by Fig. 7 .

10. Report of Test Results

10.1 Elevated-temperature strength and long-term creep data are particularly expensive and difficult to obtain. Therefore, description of the material along with the test results should be as complete as possible.

10.2 Material Characterization

10.2.1 The components which are used to fabricate the ceramic should be characterized by their individual chemical composition, purity, and powder size as well as their proportions in the total mixture.

10.2.2 The blending and sintering methods which are used to produce the ceramic should be described. The report should define such parameters as temperature, pressure, time, and size of billet.

10.2.3 Other properties which characterize the ceramic should be reported as can be obtained so that they may be correlated with the present test results. These properties include density, hardness, fracture toughness, grain size, and homogeneity. 


\subsection{Strength Tests}

10.3.1 The specimen size, the orientation of the specimen in the sintered billet, the minor and major spans of the flexure platens, and the temperature range of the strength tests should be described.

10.3.2 The results of the least-squares fit for the strength as a function of temperature should include evaluations of the temperature coefficient of strength regression, $\propto$; the regression temperature, $T_{r}$; their standard deviations; and the number of measurements.

\subsection{Creep Tests}

10.4.1 The range of temperatures and the range of applied stresses at each temperature should be reported.

10.4.2 The results of the least-squares fit for the secondary creepstrain rate as a function of stress and temperature should include evaluations of the creep index, $n$; the activiation energy, $Q$; their standard deviations; and the number of measurements.

10.4.3 The results of the least-squares fit for the secondary creepstrain rate as a function of time to failure should include evaluations of the Monkman-Grant coefficients; $\beta$ and $M$, their standards deviations, and the number of measurements.

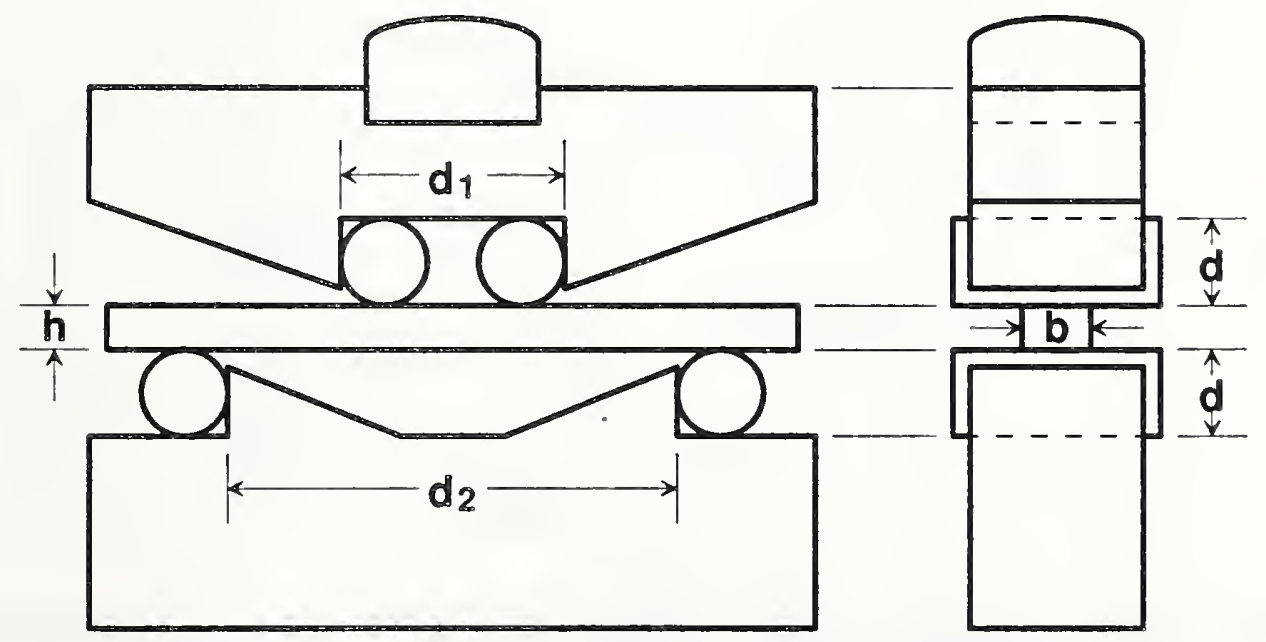

Fig. 1. Schematic of flexure platens with a beam specimen. A hemispherical compression tool is fitted to the upper platen. 


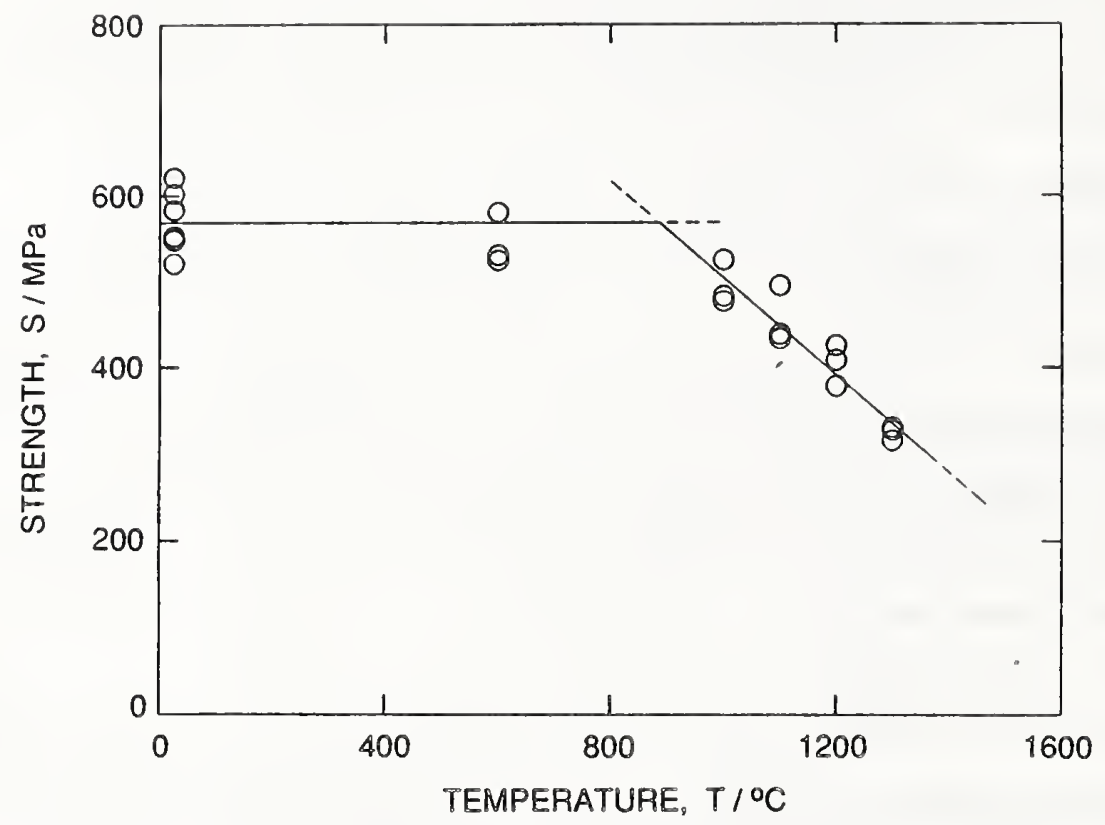

Fig. 2. Flexural strength of ceramic specimens versus temperature [11].

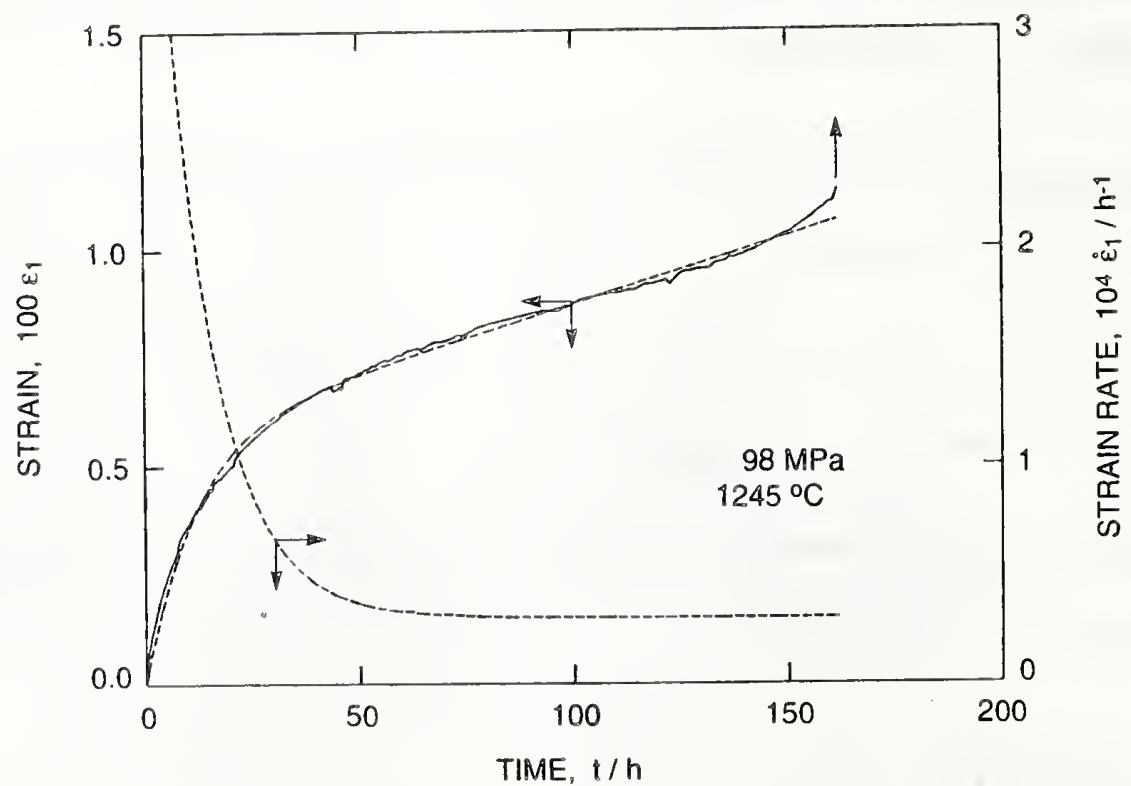

Fig. 3. Typical creep strain versus time for a ceramic flexure specimen with a fixed bending moment at a fixed temperature. The solid curve reflects load-point displacement measurements. The dashed curves show predictions from a least-squares fit [11]. 


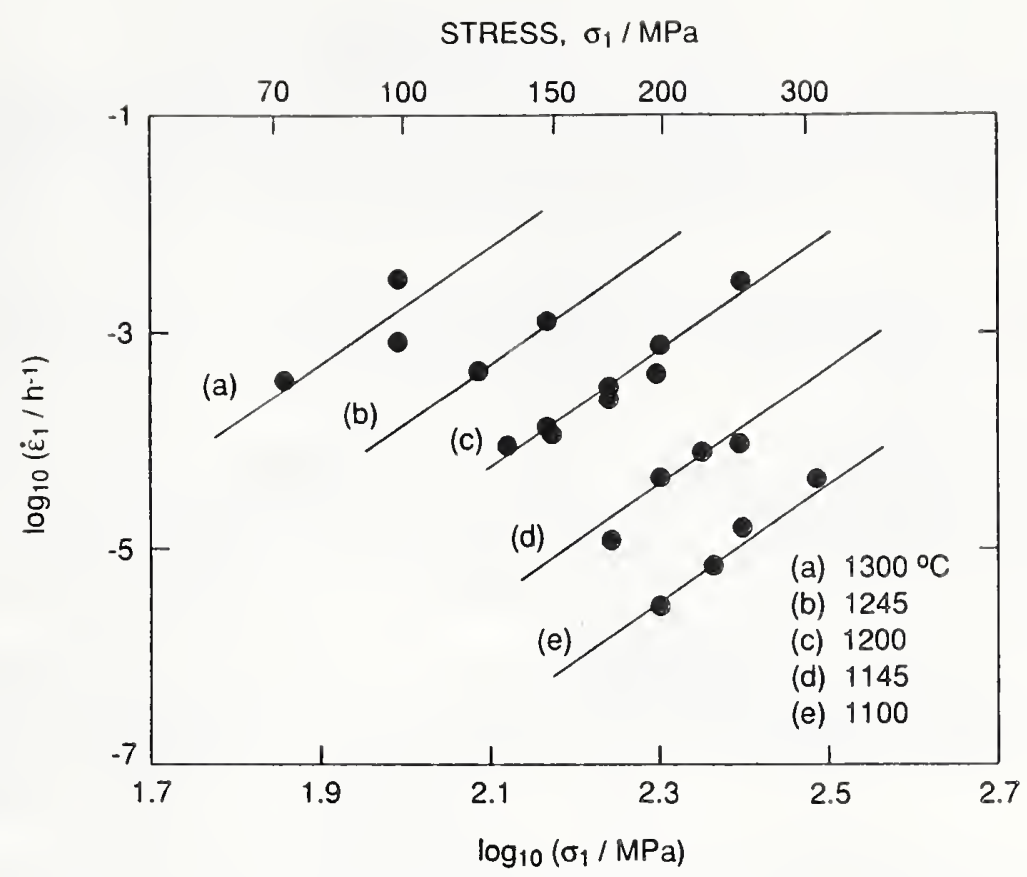

Fig. 4. Secondary creep-strain rate versus initial stress on the outer fiber at selected temperatures. The solid lines show predictions from a least-squares fit [11].

STRESS, $\sigma_{1} / \mathrm{MPa}$

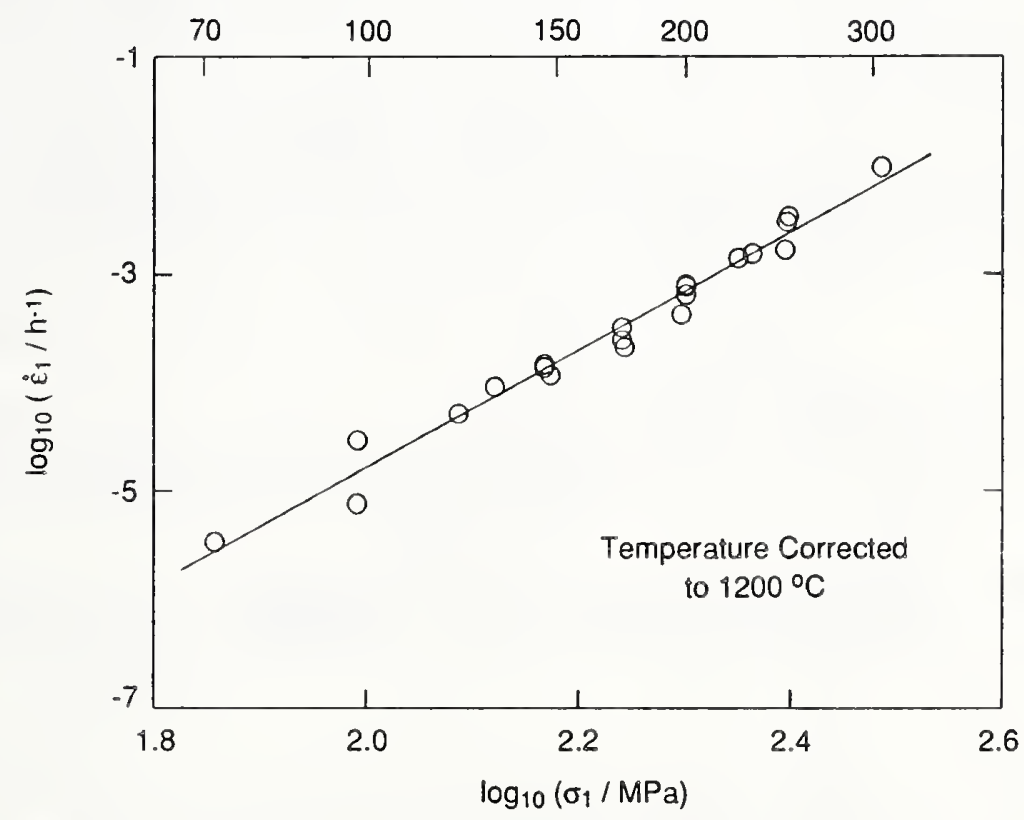

Fig. 5. Secondary creep-strain rate versus Norton's power-law function of initial stress on the outer fiber. Those points which were observed at temperatures other than $1200^{\circ} \mathrm{C}$ were temperaturecorrected to $1200^{\circ} \mathrm{C}$, using the activation energy. The solid line is a least-squares fit [11]. 


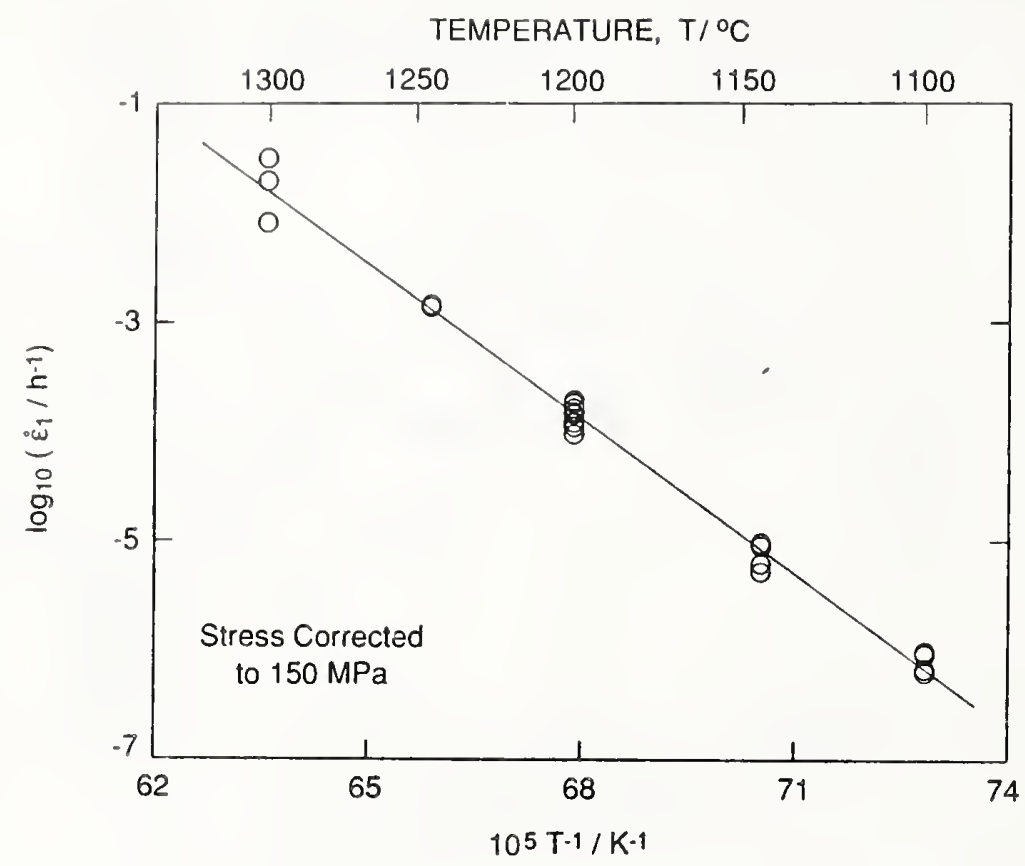

Fig. 6. Secondary creep-strain rate versus Arrhenius' inverse-temperature function. Those points which were observed at initial stresses other than $150 \mathrm{MPa}$ were stress-corrected to $150 \mathrm{MPa}$, using the creep index. The solid line is a least-squares fit [11].

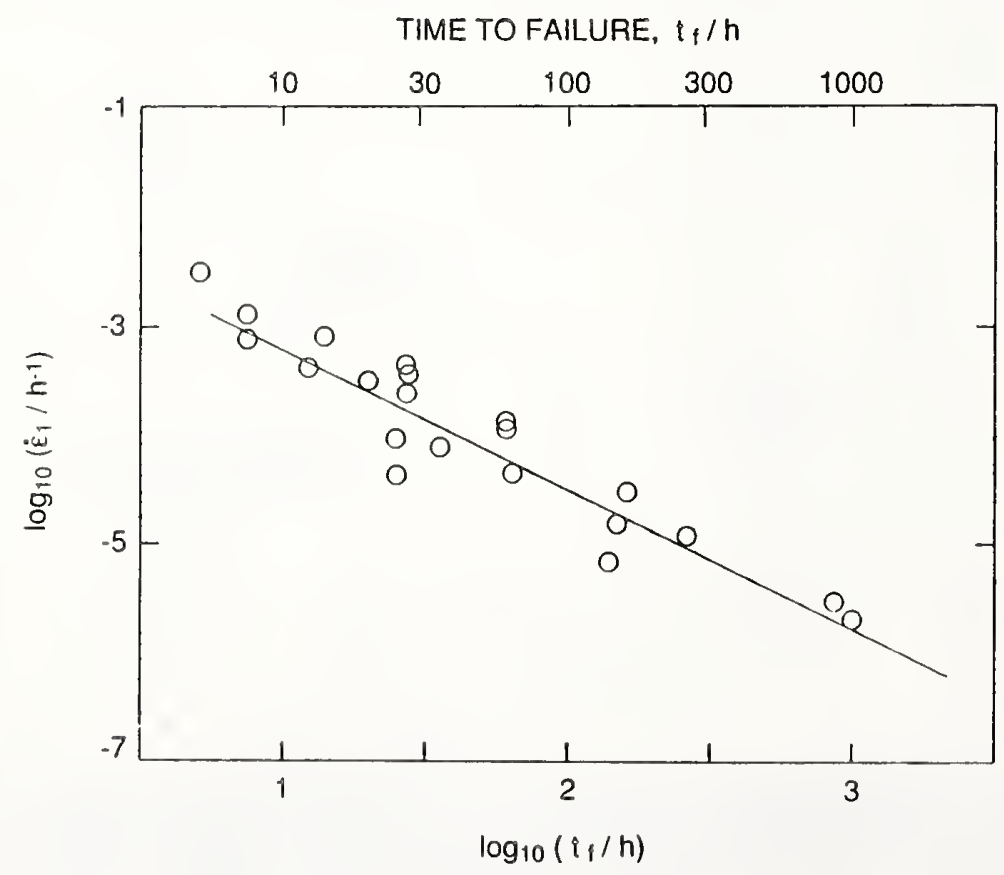

Fig. 7. Secondary creep-strain rate versus Monkman-Grant's function of time to failure. The solid line is a least-squares fit [11]. 
1. T.-J. Chuang, D.F. Carroll, and S.M. Wiederhorn, "Creep Rupture of a Metal-Ceramic Particulate Composite," Advances in Fracture Research, Proceedings of the 7 th International Conference on Fracture, Houston, TX, Pergamon Press, 1989, PP. 2965-2976.

2. T.-J. Chuang and S.M. Wiederhorn, "Damage Enhanced Creep in a Siliconized Silicon Carbide: Mechanism of Deformation,"

J. Am. Ceram. Soc., $\underline{71}$ 595-601 (1988).

3. T.-J. Chuang, S.M. Wiederhorn, and C.F. Chen, "Transient Behavior of Structural Ceramics under Flexural Creep," Third International Conference on Creep and Fracture of Engineering Materials and Structures, The Institute of Metals, London, 1987, pp. 957-973.

4. F.I. Baratta, "Requirements for Flexure Testing of Brittle Materials", Methods for Assessing the Structural Reliability of Brittle Materials, ASTM STP 844, American Society for Testing and Materials, Philadelphia, 1984, pp. 194-222.

5. C.A. Johnson, private communication, General Electric Co., Schenectady, NY, December 1988.

6. G.W. Hollenberg, G.R. Terwilliger, and R.S. Gordon, "Calculation of Stresses and Strains in Four-Point Bending Creep Tests,"

J. Am. Ceram. Soc., 54 196-199 (1971).

7. F.H. Norton, "The Flow of Ceramic Bodies at Elevated Temperatures," J.Am. Ceram. Soc., 19 129-134 (1936).

8. P.G. McVetty, "Working Stresses for High-Temperature Service," Mech. Eng., J. of the A.S.M.E., 56 149-154 (1934).

9. S. Arrhenius, Z physik. Chem., 4 226-248 (1889).

10. F.C. Monkman and N.J.Grant, "An Empirical Relationship Between Rupture Life and Minimum Creep Rate in Creep-Rupture Tests," Proc. Am. Soc. Test. Mater., $\underline{56}$ 593-620 (1956).

11. R.F. Krause, Jr., "Creep Behavior of a Silicon Carbide WhiskerReinforced Alumina Composite", unpublished work, 1989. 


\begin{tabular}{|c|c|c|c|}
\hline $\begin{array}{l}\text { U.S. DEPT. OF COMM. } \\
\text { BIBLIOGRAPHIC DATA } \\
\text { SHEET (See in Structions) }\end{array}$ & $\begin{array}{l}\text { 1. PUBLICATION OR } \\
\text { REPORT NO. } \\
\text { NISTIR-89-4127 }\end{array}$ & 2. Performing Organ. Report No. & $\begin{array}{l}\text { 3. Publication Date } \\
\text { JULY } 1989\end{array}$ \\
\hline \multicolumn{4}{|c|}{$\begin{array}{l}\text { Proposed ASTM Standard Test Method for ELEVATED TEMPERATURE FLEXURAL STRENGTH, CREEP } \\
\text { STRAIN, AND CREEP TIME TO FAILURE FOR ADVANCED CERAMICS }\end{array}$} \\
\hline \multicolumn{4}{|l|}{$\begin{array}{l}\text { 5. AUTHOR(S) } \\
\text { Ralph F. Kra }\end{array}$} \\
\hline $\begin{array}{r}\text { 6. PERFORMING ORGANI } \\
\text { NATIONAL BUREAL } \\
\text { U.S. DEPARTMENT } \\
\text { GAITHERSBURG, } M\end{array}$ & $\begin{array}{l}\text { TION (If joint or other that } \\
\text { STANDARDS } \\
\text { COMMERCE } \\
0899\end{array}$ & - see instructions) & 7. Contraed Grani No. \\
\hline
\end{tabular}

9. SPONSORING ORGANIZATION NAME AND COMPLETE ADORESS (Street, City, Stote, ZIP)

10. SUPPLEMENTARY NOTES

Document describes a computer program; SF-185, FIPS Software Summary, is attached.

11. ABSTRACT (A 200.word or less factual summary of mosi significant information. If document includes a significant bibliography or literaiure survey. mention it here)

This test method covers the determination of flexural strength, creep strain, and creep tine to failure for advanced ceramics at elevated temperatures, generally between 1200 and $2000 \mathrm{~K}$. Rectangular beam specimens, nominally $3 \mathrm{~mm} \times 4 \mathrm{~mm} \times 50 \mathrm{~mm}$, are loaded in four-point flexure. Strengths are evaluated from the maximum bending moments which are required to rupture individual specimens in dynamic loading. The creep strains of individual specimens with fixed bending moments at fixed temperatures are evaluated from load-point displacements as a function of time. The secondary creep-strain rate, which is invariant with time, is evaluated as a function of applied stress and temperature. Creep time to failure is also correlated with the secondary creep-strain rate.

12. KEY WORDS (Six to iwelve entries; alphabetical order; capitalize only proper nomes; ond seporate key words by semicolons)

applied stress; creep; elevated temperature; flexural strength; time to failure; secondary creep-strain rate

13. AVAILABILITY

Unlimited

X. For Official Distribution. Do Not Release to NTIS

Order From Superintendent of Documents, U.S. Government Printing Office, Washington, OC 20402.

14. NO. OF PRINTED PAGES

Order From National Technical Information Service (NTIS), Springfield, VA 22161 

$+1+A^{2}$

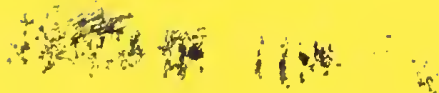

